\title{
GEOTURISMO COMO ALTERNATIVA AO TURISMO DE MASSA NA VILA DE TRINDADE, LITORAL DO PARQUE NACIONAL DA SERRA DA BOCAINA - PARATY (RIO DE JANEIRO)
}

\author{
Luana de Almeida Rangel \\ Universidade Federal do Rio de Janeiro, Departamento de Geografia, Rio de Janeiro, RJ, Brasil \\ luarangel24@gmail.com \\ Antonio José Teixeira Guerra \\ Universidade Federal do Rio de Janeiro, Departamento de Geografia, Rio de Janeiro, RJ, Brasil \\ antoniotguerra@gmail.com
}

\begin{abstract}
RESUMO
O geoturismo é uma vertente do turismo, que tem como objetivo a geoconservação e a redução do turismo de massa, agregando a participação da comunidade local ao processo de conservação. Unidades de Conservação, muitas vezes sofrem com turismo de massa, devendo estimular atividades que visem à conservação da natureza. Este artigo tem como objetivo, apresentar o potencial geoturístico da Vila de Trindade, litoral do Parque Nacional da Serra da Bocaina município de Paraty, enfatizando a importância da cultura caiçara local e propondo atividades alternativas ao turismo de massa. Para isso, foi realizada a análise qualitativa do potencial geoturístico da área com base em valores: intrínseco, cultural, estético, econômico, funcional e científico/educativo; e a geodiversidade foi valorada a partir da perspectiva de serviços ecossistêmicos. Ficou evidente que os sítios de geodiversidade necessitam de estratégias para sua conservação e reconhecimento. As ações da comunidade local, como a criação da Escola do Mar, para divulgar a cultura caiçara, são essenciais para alcançar os objetivos do geoturismo. Diante disso, o investimento em ações de conscientização para importância do geopatrimônio se fazem essenciais em Unidades de Conservação nas quais há turismo de massa.
\end{abstract}

Palavras-chave: atividade geoturística. comunidade tradicional. unidades de conservação.

\section{GEOTOURISM AS AN ALTERNATIVE TO MASS TOURISM IN TRINDADE VILLAGE, SERRA DA BOCAINA NATIONAL PARK COAST, PARATY, RIO DE JANEIRO}

\begin{abstract}
Geotourism is a part of tourism, which aims to geoconservation and reduce mass tourism, adding local communities' participation to conservation process. Conservation Units that have geodiversity sites and traditional peoples should encourage geoconservation activities. This article presents Trindade Village geotouristic potential, located in Serra da Bocaina National Park Paraty Municipality, highlighting the importance of local Caiçara culture and proposing alternatives to mass tourism developed in the area. For this, a qualitative analysis of the geotouristic potential of the area was performed based on values: intrinsic, cultural, aesthetic, economical, functional and scientific/educational; and geodiversity was valued from the perspective of ecosystem services. It was evident that geodiversity sites need geoconservation strategies. Local community actions, such as the creation of the School of the Sea to disseminate "caiçara" traditional culture, are essential to achieve geotourism goals. Therefore, it is concluded that SBNP managers should encourage local community participation in strategies for local geoconservation and should stimulate the importance of geoheritage. Therefore, investing in awareness-raising actions for the importance of geoheritage is essential in PAs in which there is mass tourism.
\end{abstract}

Keywords: Geotouristic activity. Traditional community. Protected Areas.

Caminhos de Geografia Uberlândia $\quad$ v. 20, n. $72 \quad$ Dez/2019 $\quad$ p. 506-521 Página 506




\section{INTRODUÇÃO}

O geoturismo é um ramo da atividade turística, que tem, entre outros objetivos, valorizar e incentivar a conservação do patrimônio geológico e geomorfológico (DOWLING, 2013; LOPES et al., 2011; GRAY, 2005; 2013; BRILHA, 2015; 2016), destacando a importância dos aspectos físicos na educação ambiental, pois, visa promover aos turistas, a compreensão dos sítios visitados, através da interpretação da geodiversidade (DOWLING e NEWSOME, 2006, BENTO e; RODRIGUES, 2013; RODRIGUES et al., 2016; FORTE et al., 2018).

Dowling (2013) e Jorge (2017) salientam que a ocorrência autêntica do geoturismo só acontece quando são seguidos os seguintes princípios: ter base no patrimônio geológico, promover a sustentabilidade, utilizar meios interpretativos e educativos na atividade geoturística, ter o envolvimento de comunidades locais e, por último, a satisfação do turista. Diante disso, a Educação Ambiental deve estar associada ao desenvolvimento da atividade geoturística, através da utilização de meios interpretativos. Rodrigues (2008, p. 49) destaca que a educação é a base do geoturismo, visto que:

(...) ao receber a informação, o geoturista está a aprender mediante os instrumentos interpretativos didáticos que Ihe são facultados. Quanto mais explícitos forem os fenômenos e mais apelativa for a interpretação, mais eficaz se torna a divulgação da geologia. (RODRIGUES, 2008, p. 49).

Sendo assim, o geoturismo desempenha um papel importante na valorização do geopatrimônio, sendo uma importante ferramenta em permitir o desenvolvimento sustentável (HOSE, 2006; NASCIMENTO et al., 2015; BRILHA, 2016; JORGE e GUERRA, 2016; RANGEL e GUERRA, 2018; AVELAR et al., 2018, FORTE et al., 2018).

A maioria dos geossítios e sítios de geodiversidade brasileiros estão localizados em Unidades de Conservação, o que levanta um dos grandes desafios dessas áreas: o equilíbrio entre conservação ambiental e visitação pública (BENTO e RODRIGUES, 2013). Uma estratégia para balancear a conservação e a visitação é valorar a geodiversidade. A partir disso, é possível compreender melhor o potencial dos atrativos e criar ferramentas adequadas para o manejo e gestão da área.

A presença de comunidades tradicionais em Unidades de Conservação (UCs), aliada ao desenvolvimento do geoturismo, pode se tornar uma excelente estratégia para a conservação ambiental (Jorge, 2017; Rangel, 2018). Porém, muitas vezes, essas populações locais, são vistas, pelos gestores das UCs como inimigas da proteção da natureza.

Entende-se, que no Brasil, Unidades de Conservação de proteção integral não permitem a presença de população no seu interior, mas, devido ao processo de delimitação de UCs, sem a devida consulta pública e participação social, a presença de populações, principalmente comunidades tradicionais, é frequente nessas áreas, como ocorre no Parque Nacional da Serra da Bocaina (PNSB).

A relação conflituosa entre os gestores da UC e população caiçara residente na Vila de Trindade, que se localiza no litoral do PNSB é evidente. Sobre esse aspecto, Conti e Irving (2014) destacam que a população tradicional caiçara reside na área desde antes da criação do Parque, e por se tratar de uma UC de proteção integral, há restrições nas atividades das caiçaras, como a pesca, roça, caça, entre outras.

A Vila de Trindade - considerada como Zona de Uso Intensivo do PNSB (MMA, 2002) - além de estar parcialmente inserida no PNSB, está localizada na Área de Proteção Ambiental Cairuçu. Essa sobreposição de Unidades de Conservação, associada aos conflitos fundiários existentes, à presença de população tradicional caiçara, a beleza cênica, a presença de elementos naturais significativos e o desenvolvimento do turismo de massa, revelam particularidades da área, que justificam a sua escolha como área de estudo. Sobre esses conflitos, Santos (2016) afirma que:

De acordo com o plano de manejo do PNSB, os problemas prioritários na gestão do Parque são o planejamento turístico e a expansão urbana, em especial em Trindade. Nesta área, o direito ao uso dos recursos naturais tem sido o catalisador dos conflitos, principalmente em função das proibições que limitaram o modo de vida das populações que ali vivem. Atualmente, observa-se uma mudança na forma de apropriação do recurso natural, como por exemplo, os

Caminhos de Geografia $\quad$ Uberlândia $\quad$ v. 20, n. $72 \quad$ Dez/2019 $\quad$ p. 506-521 Página 507


pescadores, que na sua maioria trabalham como barqueiros, fazendo o transporte de turistas nas praias. (SANTOS, 2016, p. 17).

Conti e Irving (2014) destacam inúmeros problemas apresentados pelos moradores de Trindade, relacionados ao desenvolvimento do turismo de massa de forma desordenada e às mudanças na cultura tradicional da população caiçara, como, por exemplo: superlotação da vila em períodos de alta temporada; o aumento do lixo e do esgoto; contaminação e degradação das áreas florestais, cachoeiras e praias. A grande quantidade de visitantes - chegando a receber mais de 10.000 pessoas nos quatro dias do Carnaval de 2017 (ICMBIO, 2017; RANGEL; et al., 2017; LOUREIRO et al., 2017) - corrobora a existência do turismo de massa na área.

Diante disso, a população local, tem na atividade turística, o principal meio de obtenção de recursos financeiros para sobrevivência. Apesar dos conflitos e da perda de algumas tradições caiçaras, Rangel (2018) destaca que a população local se empenha em divulgar para os turistas a importância dos seus costumes, na tentativa de obter visibilidade para os problemas enfrentados e reduzir os impactos do grande fluxo de turistas associados aos atrativos "sol e mar".

Neste sentido, o presente artigo tem como objetivo apresentar o potencial geoturístico da Vila de Trindade, enfatizando a importância da cultura caiçara local e destacando alternativas ao turismo de massa desenvolvido na área.

\section{METODOLOGIA}

\section{Área de estudo}

O PNSB foi criado em 1971, com área de 134.000 ha, sendo modificado em 1972, com redução para 104.000 ha. Do total, cerca de 60\% localiza-se no estado do Rio de Janeiro (municípios de Angra dos Reis e Paraty) e $40 \%$ no estado de São Paulo (municípios de São José do Barreiro, Ubatuba e Cunha) (MMA, 2002). A Vila de Trindade (VT) fica localizada no litoral do Parque (Figura 1).

Figura 1 - (a) Mapa de localização do Parque Nacional da Serra da Bocaina. (b) Mapa de localização da Vila de Trindade com identificação das praias.

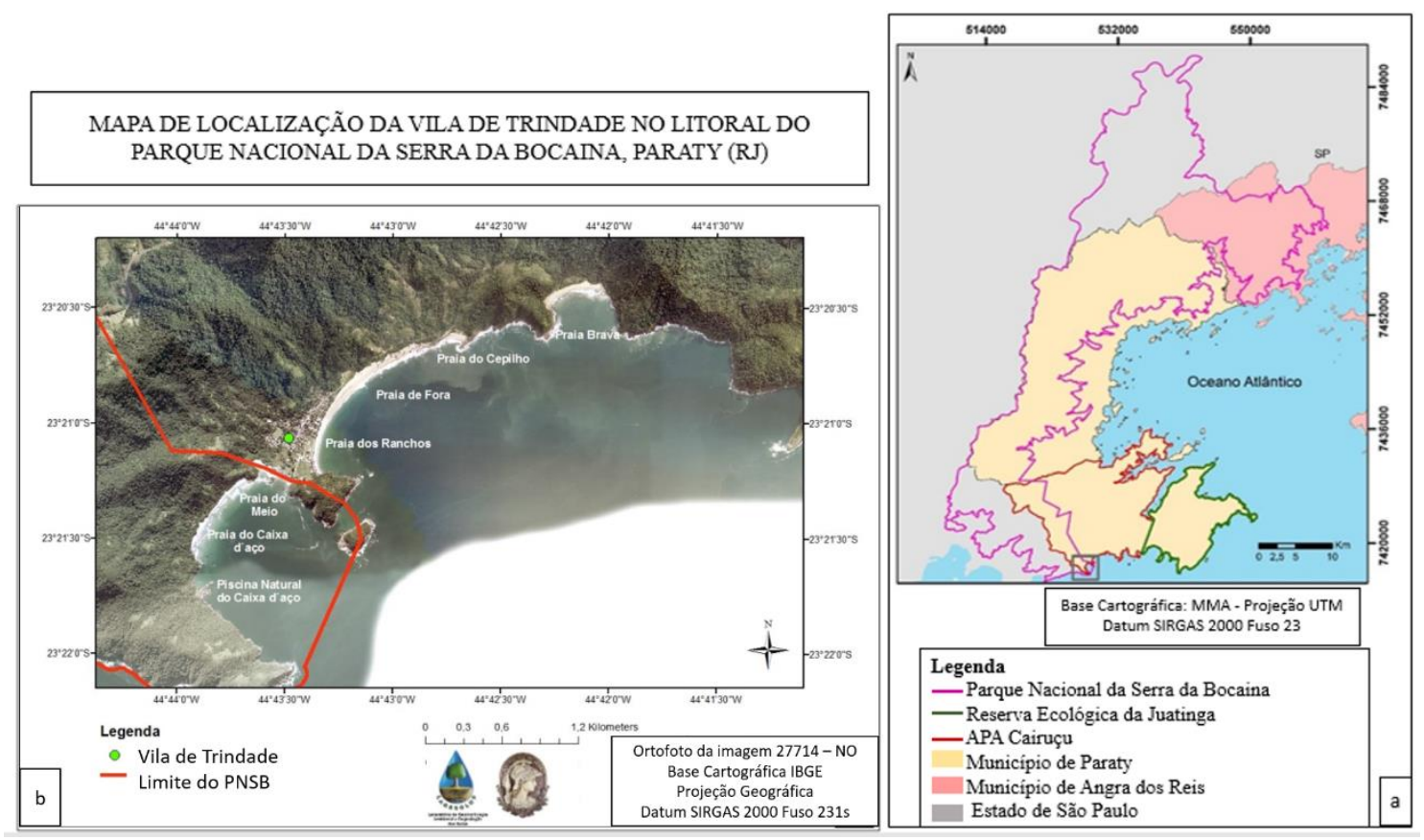

(a) Elaboração: Luana Rangel (2017). (b) Fonte: Santos (2016).

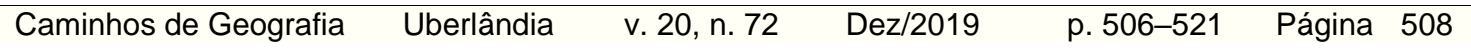


A Vila de Trindade está inserida no litoral do Parque Nacional da Serra da Bocaina, que faz parte da Reserva da Biosfera da Mata Atlântica; integra o Corredor de Biodiversidade da Serra do Mar; apresenta intenso turismo de massa e diversos conflitos associados ao uso e ocupação do solo pela presença de população caiçara; e, em uma pequena área possui inúmeros sítios de geodiversidade.

O clima da VT é influenciado pela compartimentação regional do relevo e pelo desnivelamento altimétrico, sendo classificado de acordo com Köeppen (1948), em tropical úmido, apresentando médias de temperaturas anuais em torno de $23^{\circ} \mathrm{C}$ e índices pluviométricos com valores médios de $1.850 \mathrm{~mm}$ anuais (MMA, 2002; CONTI e IRVING, 2014; RANGEL, 2018).

Com relação às características geológicas e geomorfológicas a área da VT se insere em relevo denominado Escarpas Festonadas, que apresentam declividade superior a $27^{\circ}$ (PONÇANO et al., 1981), e possuem altitudes que variam entre 950 e 1.400 metros (MMA, 2002; GUERRA et al., 2013). Já os solos superficiais da região, possuem textura argilosa, ou argilo-siltosa, correspondendo a associações de Cambissolos Háplicos Distróficos, ocorrendo também Latossolos Vermelho-Amarelos com horizonte A moderado e proeminente nos topos e encostas mais suaves (MMA, 2002; RODRIGUES et al., 2016).

Com relação à vegetação, na área de Trindade há o predomínio de Floresta Ombrófila Densa secundária, em estágio médio e avançado de recuperação (MMA, 2002).

De acordo com o MMA (2002), Trindade é um bairro de Paraty, formado originalmente por uma comunidade tradicional caiçara, que realizava atividades de roça, caça e pesca para subsistência. Parte da vila fica localizada dentro dos limites do PNSB - inclusive área marinha - e toda ela está localizada dentro da Área de Proteção Ambiental Cairuçu (APA-Cairuçu). A sobreposição das Unidades de Conservação - o Parque de proteção integral, ou seja, mais restritivo, e a APA, de uso sustentável, isto é, com menos restrições com relação às atividades desenvolvidas - intensifica os conflitos de uso e ocupação do solo já existentes.

\section{Análise da atividade turística}

Para o desenvolvimento da pesquisa foram realizados trabalhos de campo de observação durante os anos de 2016 e 2017, onde foram analisadas e fotografadas transformações da paisagem baseadas nos impactos da atividade turística e foram selecionados possíveis pontos de interesse geoturístico, que podem ser utilizados em roteiros geoturísticos. Além disso, foram analisadas algumas medidas propostas pela gestão do Parque para reduzir o impacto do turismo de massa.

O potencial geoturístico foi avaliado a partir da metodologia proposta por Gray $(2005,2008)$ e adaptada por Santos (2012). Os autores destacam os seguintes aspectos: valor intrínseco, valor cultural, valor estético, valor econômico, valor funcional e valor científico/educativo (figura 2). Essas categorias e seus valores estão diretamente relacionados com o desenvolvimento do geoturismo. 
Figura 2 - Categorias de valores da geodiversidade de acordo com Gray (2004) e Santos (2012).

\begin{tabular}{|c|c|}
\hline Tipos de valor & Aspectos \\
\hline $\begin{array}{l}\text { I - Valor Intrínseco } \\
\text { Valor de um determinado elemento, independente de parâmetros } \\
\text { antropocêntricos. Pereira (2010) reúne nesta categoria os } \\
\text { parâmetros associados diretamente aos aspectos inerentes ao } \\
\text { geossitio, independentemente do seu eventual uso, ou de uma } \\
\text { avaliação funcional do local, a saber: raridade, integridade, } \\
\text { vulnerabilidade associada aos processos naturais e a variedade de } \\
\text { elementos da geodiversidade que o local apresenta. }\end{array}$ & $\begin{array}{l}\text { 1. Natureza abiótica independente da } \\
\text { avaliação humana }\end{array}$ \\
\hline $\begin{array}{l}\text { II - Valor cultural } \\
\text { Relativo à relevância de um determinado elemento da } \\
\text { geodiversidade para um determinado grupo social. Segundo Gray } \\
\text { (2004), consiste em uma das categorias mais práticas e objetivas } \\
\text { dentre os valores atribuidos à geodiversidade. A sacralização de } \\
\text { geoformas, ou a denominação de locais em associação com } \\
\text { geoformas caracteristicas, såo exemplos desta valorizaça e da } \\
\text { significância dos elementos do meio físico para a humanidade. }\end{array}$ & $\begin{array}{l}\text { 2.Folclore } \\
\text { 3.Arqueológico/Histórico } \\
\text { 4. Espiritual } \\
\text { 5. Sentido do lugar }\end{array}$ \\
\hline $\begin{array}{l}\text { III - Valor Estético } \\
\text { Possuem este valor todas aquelas paisagens } \\
\text { geológicas/geomorfológicas que causam um deslumbramento de } \\
\text { seu público, que são alvo de atividades de lazer, contemplação ou } \\
\text { inspiração artística. }\end{array}$ & $\begin{array}{l}\text { 6. Paisagens locais } \\
\text { 7.Geoturismo } \\
\text { 8. Atividades de lazer } \\
\text { 9. Apreciação à distância } \\
\text { 10.Atividades voluntárias } \\
\text { 11. Inspiração artística }\end{array}$ \\
\hline $\begin{array}{l}\text { IV - Valor Econômico } \\
\text { Essa atribuição está ligada à total dependência do homem perante } \\
\text { os materiais geológicos para atividades como produção de } \\
\text { energia, construção civil, fabricação de uma infinidade de } \\
\text { produtos, extraçăo de água subterrânea, gemas para joalheria, etc. }\end{array}$ & $\begin{array}{l}\text { 12. Energia } \\
\text { 13. Minerais industriais } \\
\text { 14. Minerais metálicos } \\
\text { 15. Minerais para construção } \\
\text { 16. Gemas } \\
\text { 17. Fósseis }\end{array}$ \\
\hline $\begin{array}{l}\text { V - Valor Funcional } \\
\text { Valor atribuido aos elementos da geodiversidade em decorrência } \\
\text { da sua função como substrato onde se estabelecem e desenvolvem } \\
\text { as ações antrópicas e onde se instalam os biomas e elementos da } \\
\text { biodiversidade. }\end{array}$ & $\begin{array}{l}\text { 18. Solo } \\
\text { 19. Plataformas } \\
\text { 20. Armazenamento e reciclagem } \\
\text { 21. Saúde } \\
\text { 22. Enterro } \\
\text { 23. Controle de poluição } \\
\text { 24. Química da água } \\
\text { 25. Funções do solo } \\
\text { 26. Funções do geossistema } \\
\text { 27. Funções do ecossistema }\end{array}$ \\
\hline $\begin{array}{l}\text { VI - Valor Científico } \\
\text { De acordo com Pereira (2010), esta categoria de valor trata da } \\
\text { relevância de alguns elementos da geodiversidade na } \\
\text { representação de processos relativos aos fenômenos naturais do } \\
\text { planeta, prestando um papel educacional que, muitas vezes, se } \\
\text { reflete na quantidade e qualidade de trabalhos de pesquisa } \\
\text { realizados a respeito deste elemento ou local. }\end{array}$ & $\begin{array}{l}\text { 28. Pesquisa cientifica } \\
\text { 29. História da Terra } \\
\text { 31. Monitoramento ambiental } \\
\text { 32. Educação e formação de } \\
\text { professores }\end{array}$ \\
\hline
\end{tabular}

Fonte: Jorge (2017). 
Gray (2013) realizou uma atualização da metodologia elaborada em 2005 e propôs a valoração da geodiversidade a partir da perspectiva de serviços ecossistêmicos. Sendo assim, o autor, definiu cinco categorias de serviços providos pela geodiversidade apresentadas na figura 3.

Figura 3 - Atributos avaliados para valoração da geodiversidade

\begin{tabular}{|c|c|c|}
\hline Serviços Ecossistêmicos & Atributos avaliados & $\begin{array}{c}\text { Valoração da } \\
\text { importância do sítio } \\
\text { de geodiversidade } \\
\text { para os atributos }\end{array}$ \\
\hline Serviços de regulação & \begin{tabular}{llr} 
Processos & oceânicos & $\mathrm{e}$ \\
atmosféricos; & \multicolumn{2}{c}{ processos } \\
terrestres; controle de & de \\
inundações; quantidade & $\mathrm{e}$ \\
qualidade da água. &
\end{tabular} & $\begin{array}{l}\text { A - Alto } \\
\text { M-Médio } \\
\text { B - Baixo } \\
\text { I - Inexistente }\end{array}$ \\
\hline Serviços de suporte & $\begin{array}{l}\text { Processos do solo; provisão } \\
\text { de habitats; a terra como uma } \\
\text { plataforma; armazenamento. }\end{array}$ & $\begin{array}{l}\text { A - Alto } \\
\text { M-Médio } \\
\text { B - Baixo } \\
\text { I - Inexistente }\end{array}$ \\
\hline Serviços de provisionamento & $\begin{array}{l}\text { Comida e bebida; nutrientes e } \\
\text { minerais para crescimento } \\
\text { saudável; combustíveis; } \\
\text { materiais para construção; } \\
\text { minerais industriais; produtos } \\
\text { ornamentais; fósseis. }\end{array}$ & $\begin{array}{l}\text { A - Alto } \\
\text { M-Médio } \\
\text { B - Baixo } \\
\text { I - Inexistente }\end{array}$ \\
\hline Serviços culturais & $\begin{array}{l}\text { Qualidade } \\
\text { geoturismo e ambiental; } \\
\text { significado cultural, espiritual } \\
\text { e histórico; inspiração } \\
\text { artística; desenvolvimento } \\
\text { social. }\end{array}$ & $\begin{array}{l}\text { A - Alto } \\
\text { M - Médio } \\
\text { B - Baixo } \\
\text { I - Inexistente }\end{array}$ \\
\hline Serviços de conhecimento & $\begin{array}{l}\text { História da terra; } \\
\text { conhecimento dos processos } \\
\text { físicos; história da pesquisa; } \\
\text { monitoramento ambiental; } \\
\text { educação e empregos. }\end{array}$ & $\begin{array}{l}\text { A - Alto } \\
\text { M-Médio } \\
\text { B - Baixo } \\
\text { I - Inexistente }\end{array}$ \\
\hline
\end{tabular}

Fonte: Adaptado de Gray (2013)

Optou-se, portanto, por utilizar as duas metodologias de valoração da geodiversidade propostas por Gray $(2005 ; 2013)$ para análise da Piscina Natural Caixa D’Aço, que é o principal atrativo da Vila de Trindade.

\section{RESULTADOS E DISCUSSÃO}

Vallejo (2013) destaca que de todas as categorias do SNUC, os parques públicos são os que mais sofrem com o uso público. No litoral do PNSB é possível observar o desenvolvimento do 
uso público de forma desordenada, principalmente em épocas de grande fluxo de visitantes (verão e feriados prolongados).

Na figura 4 são apresentados alguns dos impactos do turismo de massa observados na Vila de Trindade, bem como estratégias da gestão do Parque para tentar reduzir esses impactos, principalmente no principal atrativo que é a Piscina Natural Caixa D’Aço.

Figura 4 - Turismo de massa e ações da gestão do PNSB para tentar reduzir o uso público desordenado. (a) Folheto informativo do PNSB avisando sobre o limite do número de visitantes.

(b) Atividade de venda de bebidas irregular na PNC. (c) Estrutura improvisada para venda de bebidas na piscina natural Caixa D'Aço. No detalhe: acúmulo de lixo e placa, instalada pelo

PNSB, destruída. (d) Barco dentro da PNC colocando em risco os visitantes e impactando negativamente no ecossistema.
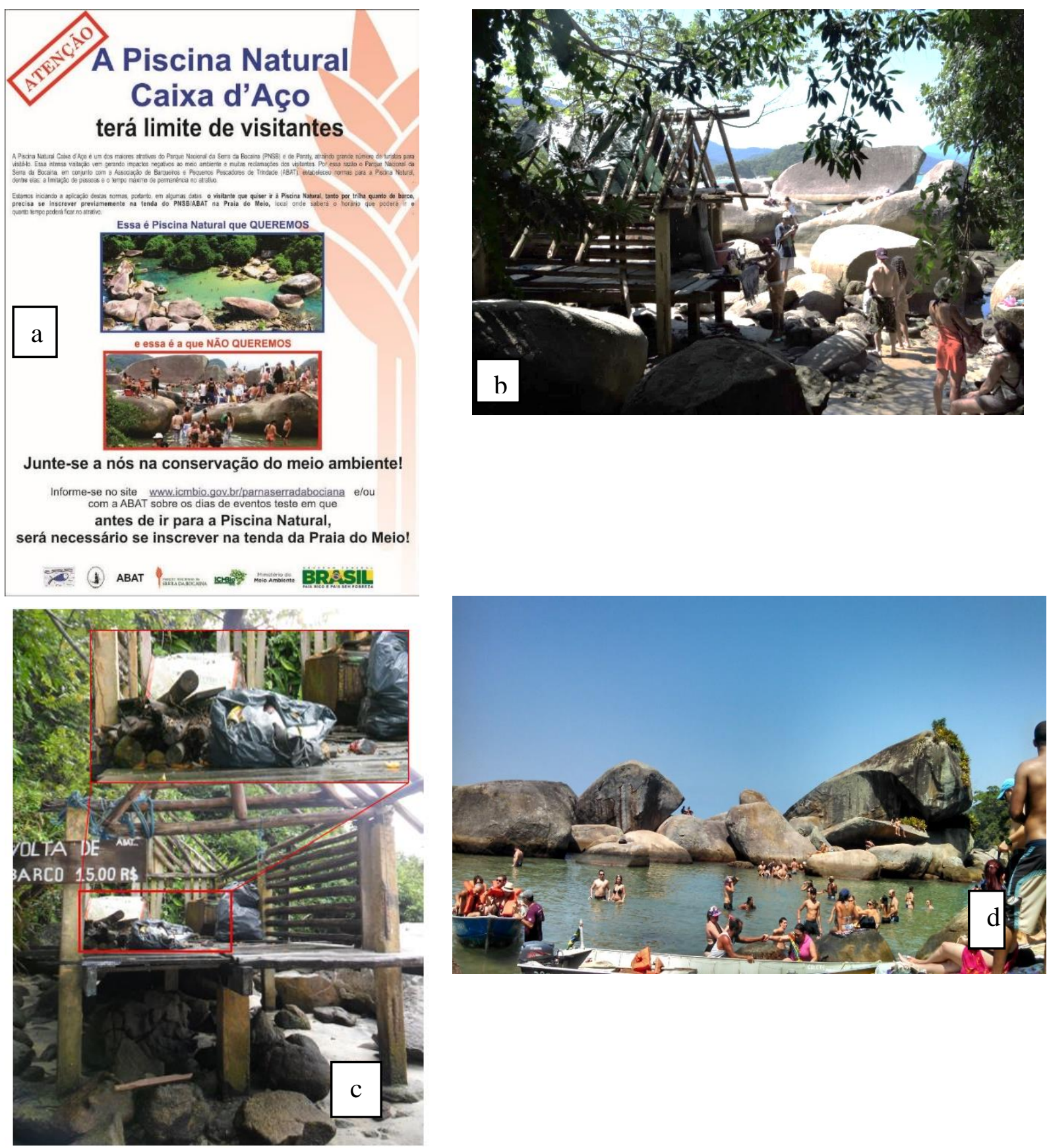
(a) Fonte: ICMBIO (2014). (b) Foto: Stella Peres Mendes (2014). (c) Foto: autor (2016). (d) Foto: autor (2014).

Em 2014, o ICMBio, propôs limitar o número de pessoas ao mesmo tempo na piscina natural Caixa D'Aço, visando reduzir os impactos ambientais da visitação. Foram realizados testes sendo definido o limite de 59 pessoas ao mesmo tempo. Porém, essa estratégia não foi mantida, sendo realizadas em situações pontuais. A realidade continua evidenciando o uso público desordenado conforme observado na figura 5.

Figura 5 - Superlotação da piscina natural Caixa D’Aço em 26 de janeiro de 2018.

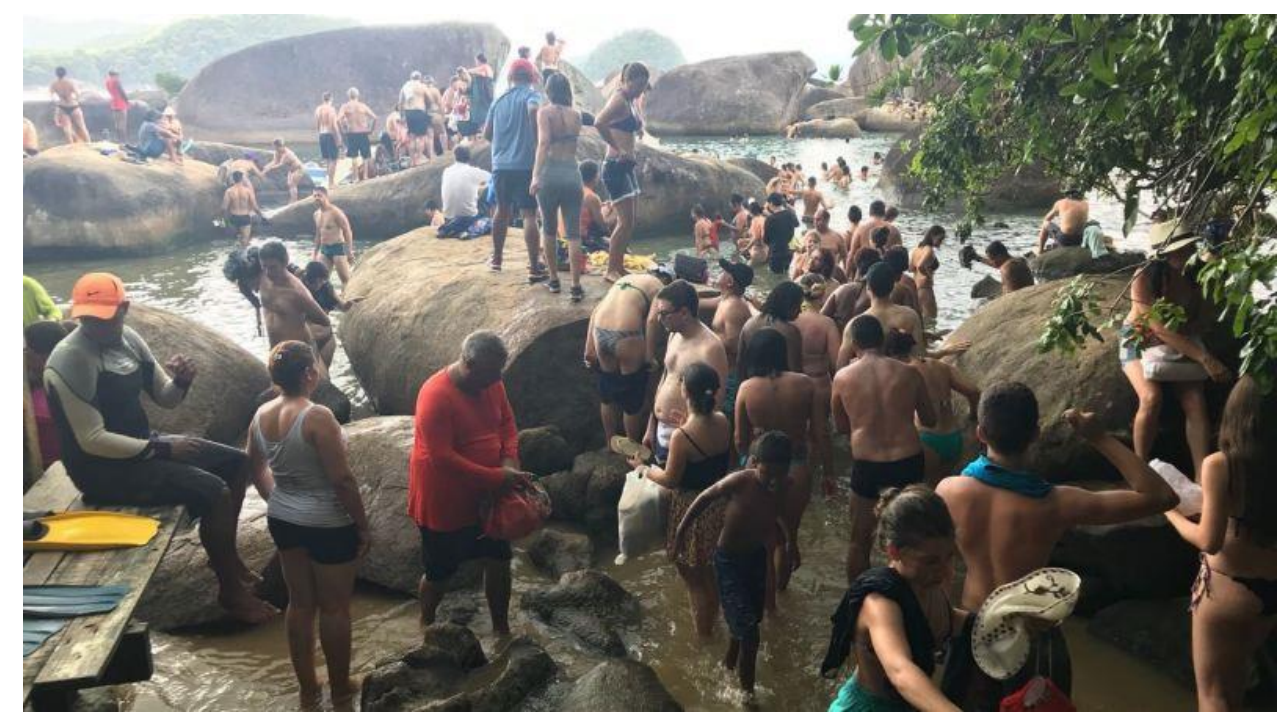

Foto: Gabriel Toledo (2018)

O potencial geoturístico foi avaliado a partir das metodologias propostas por Gray (2005) e Santos (2012). Na figura 6 são apresentados os potenciais da atividade geoturística e a valoração da geodiversidade para a Vila de Trindade, nas quais são adotados os valores: intrínseco, cultural, estético, econômico e funcional. Optou-se por realizar a avaliação qualitativa para toda a vila de Trindade, dentro dos limites e na zona de amortecimento do Parque, pois, entende-se que a compartimentação e exclusão das situações observadas na zona de amortecimento, são essenciais para compreender e embasar o desenvolvimento do geoturismo dentro do PNSB. 
Figura 6 - Avaliação qualitativa da geodiversidade na vila de Trindade (dentro e fora dos limites do PNSB), a partir da metodologia de Gray (2004).

\begin{tabular}{|c|c|c|}
\hline I - Valor intrinseco & & Meio abiótico livre de avaliação \\
\hline \multirow{3}{*}{ II - Valor cultural } & Sentido de lugar & $\begin{array}{l}\text { Comunidade caiçara com } \\
\text { identidade, hảbitos próprios. } \\
\text { Sentimento de pertencimento. }\end{array}$ \\
\hline & Espiritual/Religioso & $\begin{array}{l}\text { Lendas caiçaras representam a } \\
\text { conexão espiritual da população } \\
\text { tradicional com o lugar. }\end{array}$ \\
\hline & Histórico & $\begin{array}{l}\text { A VT foi sido habitada por indios, } \\
\text { portugueses e possiveis piratas. } \\
\text { Hoje a história é marcada pela } \\
\text { cultura tradicional caiçara e pelos } \\
\text { movimentos de luta para se } \\
\text { manter no território. }\end{array}$ \\
\hline \multirow{4}{*}{ III - Valor estético } & Paisagens & $\begin{array}{l}\text { Beleza cênica significativa. } \\
\text { Praias, cachoeiras, rios, e sitios de } \\
\text { geodiversidade se destacam. }\end{array}$ \\
\hline & Atividades de lazer & $\begin{array}{l}\text { O ecoturismo e o turismo de } \\
\text { aventura saao atividades potenciais } \\
\text { para ser desenvolvido nas trilhas }\end{array}$ \\
\hline & Geoturismo & $\begin{array}{l}\text { Apesar do apelo turistico estar } \\
\text { associado principalmente à } \\
\text { formação geomorfológica e } \\
\text { geológica da piscina natural Caixa } \\
\text { D'Aço, das cachoeiras da Pedra } \\
\text { que Engole e do afloramento } \\
\text { rochoso Cabeça do fndio, não há } \\
\text { incentivo ou propostas de gestão } \\
\text { para o geoturismo }\end{array}$ \\
\hline & Apreciação à distância & $\begin{array}{l}\text { Algumas feições geológicas e } \\
\text { geomorfológicas da área são } \\
\text { contempladas pelos visitantes, } \\
\text { como o afloramento rochoso } \\
\text { "Cabeça de indio". }\end{array}$ \\
\hline \multirow[t]{2}{*}{ IV - Valor econômico } & Solos & $\begin{array}{l}\text { Os solos possuiam, antes da } \\
\text { instalação do PNSB, valor } \\
\text { econômico para a população } \\
\text { caiçara, visto que, realizavam } \\
\text { plantio de alimentos para } \\
\text { subsistência. Atualmente, é } \\
\text { motivo de disputa entre a } \\
\text { população local e uma empresa } \\
\text { turistica multinacional que tenta } \\
\text { explorar as terras. }\end{array}$ \\
\hline & Rochas & $\begin{array}{l}\text { A ocorrencia de granitos } \\
\text { isotrópicos tipo charnoquitos, } \\
\text { principalmente o denominado } \\
\text { "Verde Ubatuba" devem ser } \\
\text { destacadas pelo seu valor } \\
\text { comercial e ornamental. }\end{array}$ \\
\hline
\end{tabular}




\begin{tabular}{|c|c|c|}
\hline \multirow{4}{*}{ V-Valor funcional } & Funçdes do solo & $\begin{array}{l}\text { Construçăo de pousadas, } \\
\text { campings e restaurantes (as vezes } \\
\text { de forma desordenada) săo as } \\
\text { atividades mais comuns. }\end{array}$ \\
\hline & Quimica da agua & $\begin{array}{l}\text { A VT possui diversas nascentes e } \\
\text { o recurso hidrico abastece a } \\
\text { própria vila. Necessitando de } \\
\text { especial interesse, pois VT não } \\
\text { possui sistema de saneamento } \\
\text { adequado (grande parte dos } \\
\text { efluentes são lançados em } \\
\text { córregos e no mar). }\end{array}$ \\
\hline & Funçס̃es do geossistema & $\begin{array}{l}\text { Elevada importância da àrea para } \\
\text { manutençåo da biodiversidade } \\
\text { caracteristica da Mata Atlântica e } \\
\text { da geodiversidade caracteristica } \\
\text { da Serra do Mar. O mosaico de } \\
\text { UCs existente na área é } \\
\text { fundamental para conservação do } \\
\text { ambiente natural e conexões com } \\
\text { outros ambientes. }\end{array}$ \\
\hline & Funçס̄es do ecossistema & $\begin{array}{l}\text { Área de Mata Atlântica com papel } \\
\text { essencial para manutenção de } \\
\text { diferentes ecossistemas, } \\
\text { permitindo conexão através de } \\
\text { corredor ecológico com outras } \\
\text { Unidades de Conservaçảo. }\end{array}$ \\
\hline \multirow{4}{*}{ VI - Valor cientifico } & História da Terra & $\begin{array}{l}\text { A área apresenta presença de } \\
\text { zonas de cisalhamento e falhas } \\
\text { que conferem caracteristicas como } \\
\text { o encaixamento de determinados } \\
\text { rios da região da Costa Verde. } \\
\text { Alèm disso, o sub-gráben de } \\
\text { Paraty está associado ao rifte } \\
\text { litorâneo, compondo o gráben da } \\
\text { Guanabara. }\end{array}$ \\
\hline & Monitoramento ambiental & $\begin{array}{l}\text { As análises da qualidade dos } \\
\text { solos, da diversidade de espécies } \\
\text { de fauna e flora, do impacto do } \\
\text { uso público e a influéncia da } \\
\text { atividade turistica no ambiente } \\
\text { natural, săo realizadas. }\end{array}$ \\
\hline & $\begin{array}{l}\text { Educaçảo e formaçảo dos } \\
\text { professores }\end{array}$ & $\begin{array}{l}\text { A VT recebe pesquisadores de } \\
\text { diversas áreas e trabalhos de } \\
\text { campo educacionais, } \\
\text { principalmente voltados para o } \\
\text { conhecimento da cultura caiçara } \\
\text { local e entendimento dos conflitos } \\
\text { pelo uso da terra e manutenção da } \\
\text { tradição local. }\end{array}$ \\
\hline & Pesquisa cientifica & $\begin{array}{l}\text { A área da VT vem sendo estudada } \\
\text { por diversos pesquisadores devido } \\
\text { aos inúmeros conflitos entre a } \\
\text { população caiçara, a gestão do } \\
\text { PNSB e especuladores } \\
\text { imobiliários. }\end{array}$ \\
\hline
\end{tabular}

Dentre os aspectos e valores citados no quadro, merecem destaque o valor estético, pela beleza cênica da biodiversidade e da geodiversidade local e o valor econômico das rochas, associado à presença do Granito Verde Ubatuba, que possui elevado valor comercial e ornamental. Além disso, outro ponto a ser

$\begin{array}{lllll}\text { Caminhos de Geografia } & \text { Uberlândia } & \text { v. 20, n. } 72 & \text { Dez/2019 } & \text { p. 506-521 Página } 515\end{array}$


destacado é o elevado valor cultural, pela importância da tradição e cultura caiçara existente em Trindade. O rancho caiçara foi reformado pela gestão do PNSB, em 2013, e está sendo construída, pela comunidade local, a Escola do Mar, uma casa de farinha que será utilizada para divulgação das tradições caiçaras (Figura 7).

Figura 7 - (a) Exemplos de pontos de interesse geológicos e de beleza cênica na Praia do Meio no detalhe (em vermelho) os blocos que formam a piscina natural Caixa D'Aço. (b) Escola do Mar e casa de farinha caiçara em Trindade. Local será utilizado para divulgação da cultura caiçara e ações educativas.
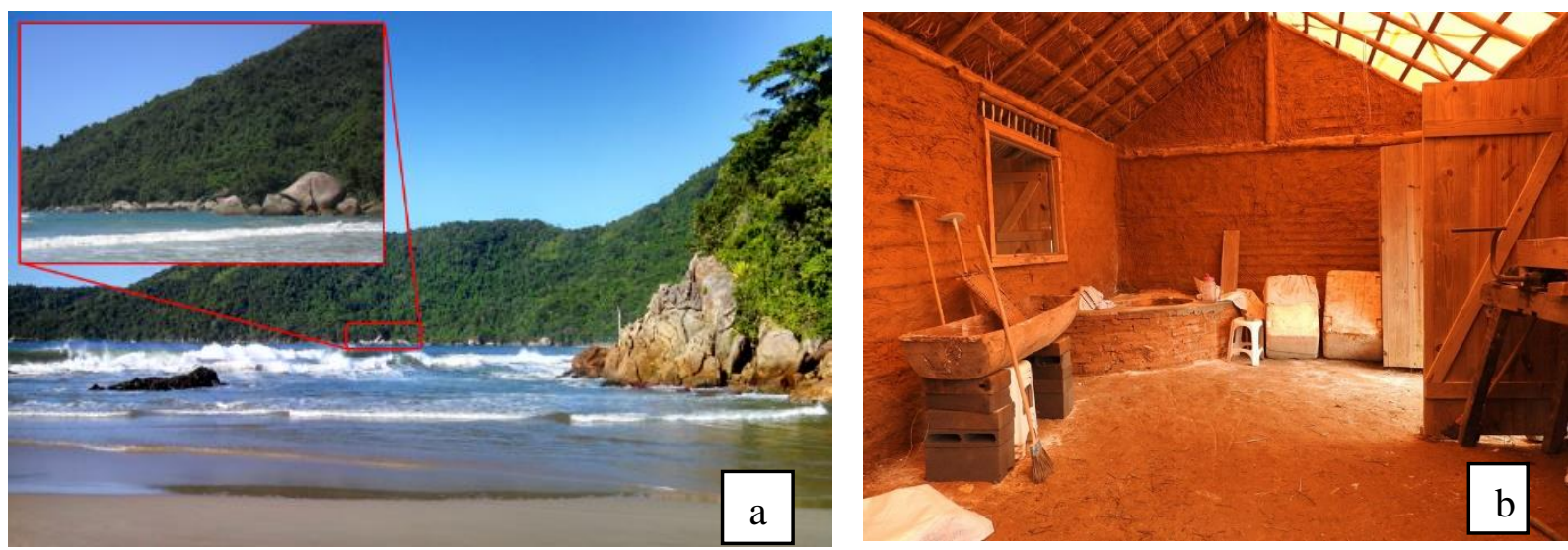

(a) Foto: Autor (2016). (b) Fonte: Reprodução Associação de Moradores de Trindade (AMOT) (2018).

Analisando a Piscina Natural Caixa D'Aço, de acordo com os serviços ecossistêmicos da geodiversidade propostos por Gray (2013), foi possível valorar os aspectos apresentados na figura 8.

Apesar da relevância didática e para o desenvolvimento de pesquisas, existem poucos trabalhos sobre a Vila de Trindade, sendo a maioria relacionados aos conflitos entre a gestão do Parque e a população Caiçara residente (Conti, 2011; Conti et al. 2011; Conti e Antunes, 2012; Conti e Irving, 2014; Santos, 2016; Rangel, 2018). Fica evidente a necessidade da realização de mais pesquisas relacionadas ao geoturismo e à relevância geológica-geomorfológica não só da Piscina Natural Caixa D'Aço, mas também, de outras feições localizadas no litoral no Parque, como a cachoeira do Pontal e o afloramento rochoso Cabeça do Índio (Figura 9). 
Figura 8 - Valoração do sítio de geodiversidade da piscina natural Caixa D'Aço, a partir dos serviços ecossistêmicos

\begin{tabular}{|c|c|c|}
\hline Serviços Ecossistêmicos & Atributos avaliados & $\begin{array}{l}\text { Valoração da } \\
\text { importância do sitio } \\
\text { de geodiversidade } \\
\text { para os atributos }\end{array}$ \\
\hline Serviços de regulação & $\begin{array}{l}\text { Importância dos recursos hidricos } \\
\text { locais para abastecimento da area. } \\
\text { A Piscina natural é importante } \\
\text { para qualidade da água do mar e } \\
\text { reprodução de espécies marinhas } \\
\text { de grande fragilidade. }\end{array}$ & Alto \\
\hline Serviços de suporte & $\begin{array}{l}\text { A piscina é habitat de diferentes } \\
\text { espécies de fauna marinha. }\end{array}$ & Médio \\
\hline $\begin{array}{ll}\text { Serviços } & \text { de } \\
\text { provisionamento } & \end{array}$ & $\begin{array}{l}\text { Por estar inserida em uma Unidade } \\
\text { de Conservação de proteção } \\
\text { integral não ocorre extração de } \\
\text { minerais. }\end{array}$ & Inexistente \\
\hline Serviços culturais & $\begin{array}{l}\text { Possui elevada importància para } \\
\text { qualidade ambiental local; grande } \\
\text { potencial para atividade } \\
\text { geoturistica, ecoturistica, de lazer } \\
\text { e de praticas de educação } \\
\text { ambiental. Para a comunidade } \\
\text { local, representa potencialidade de } \\
\text { desenvolvimento social; está } \\
\text { atrelada a aspectos culturais e } \\
\text { espirituais da populaçào caicara. }\end{array}$ & Alto \\
\hline Serviços de conhecimento & $\begin{array}{l}\text { E um sitio importante para } \\
\text { monitoramento ambiental, pois } \\
\text { recebe grande número de } \\
\text { visitantes e necessita de } \\
\text { acompanhamento dos impactos. } \\
\text { Representa, para comunidade } \\
\text { local, importante fonte de } \\
\text { empregos (através do guiamento } \\
\text { nas trilhas e no transporte de barco } \\
\text { que permitem acesso à piscina). } \\
\text { Pode ser utilizada para trabalhos } \\
\text { de pesquisa em campo devido à } \\
\text { geodiversidade e ocorrência de } \\
\text { processos de intemperismo, } \\
\text { esfoliaçà̃o esferoidal, fratura em } \\
\text { blocos rochosos. Potencial para } \\
\text { atividades de Educaçào Ambiental } \\
\text { com turistas e membros da } \\
\text { comunidade. }\end{array}$ & Alto \\
\hline
\end{tabular}


Figura 9 - Feições de geodiversidade presentes na Vila de Trindade. (a) Vista da Cabeça do Índio (no detalhe) a partir da Praia da Caixa D’Aço. (b) Cachoeira do Pontal Poço Fundo, na Vila de Trindade, Paraty (RJ).
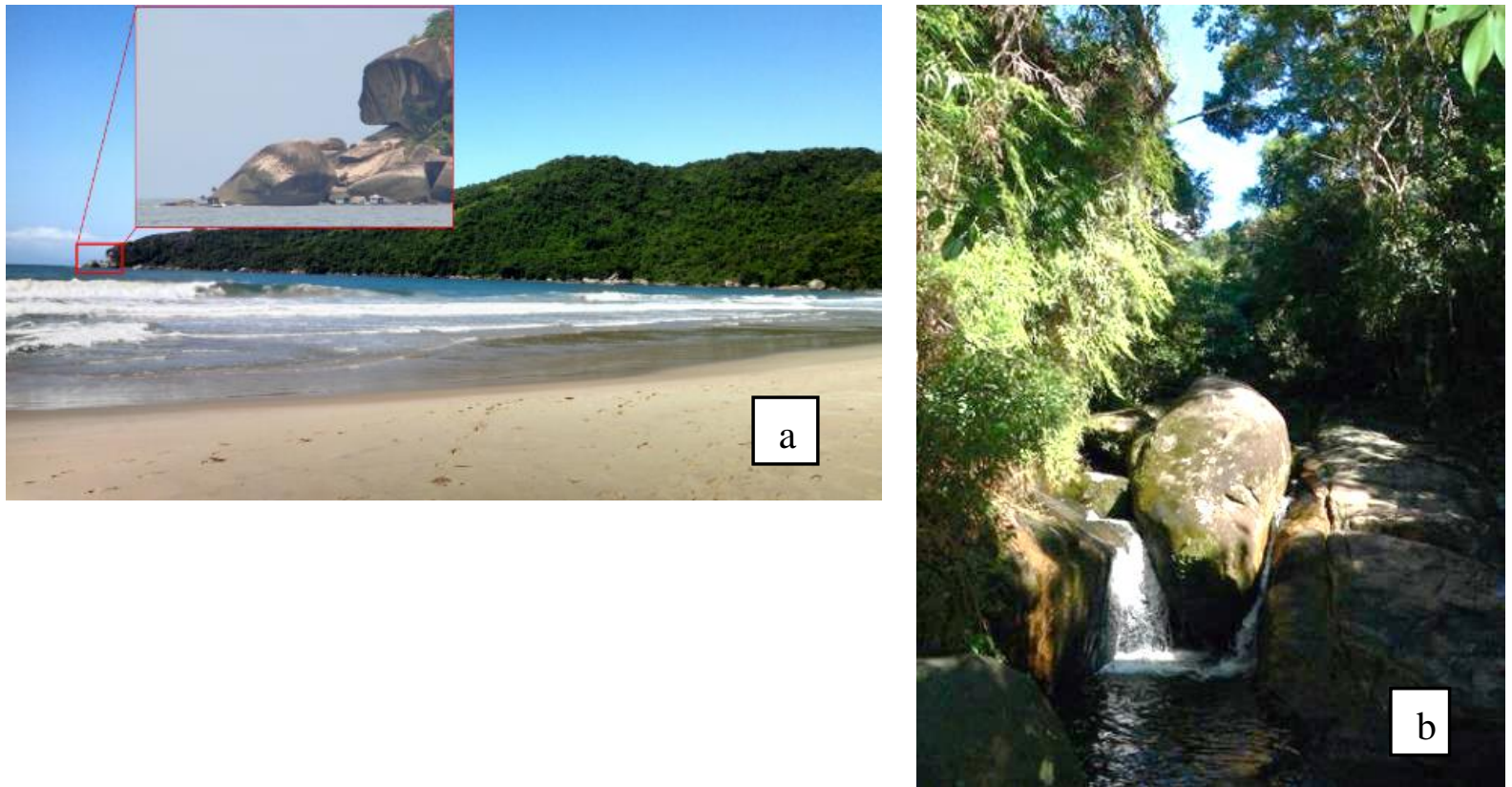

Fotos: (a) Álvaro B.S. Jr. (2010) e (b) O autor (2016).

A partir da valoração da geodiversidade da piscina natural Caixa D'Aço ficou evidente que ela possui alto valor intrínseco, estético e econômico, visto que, se configura como principal atrativo turístico da Vila de Trindade, pelo grande apelo ao turismo "sol e praia", pela sua beleza cênica e pela importância que possui para a comunidade local (estímulo econômico devido à atividade turística). Já os aspectos funcional e didático/científico possuem valor mediano. Com relação aos serviços ecossistêmicos, a piscina possui alto valor para os serviços de regulação, culturais e de conhecimento; médio valor para o serviço de suporte; e o serviço de provisionamento é inexistente.

Atualmente, diversas ações de educação ambiental e de valorização da comunidade caiçara são realizadas pela Associação de Moradores de Trindade (AMOT), como instalação de lixeiras recicláveis e mutirões para coleta de lixo; festas de incentivo à cultura local e outras ações para conscientização do turista. Sobre as festas realizadas pela comunidade local, Santos (2016, p. 74) destaca que: "(...) o Fórum de Comunidades Tradicionais de Paraty organizou o Festejo Caiçara, na tentativa de valorização da cultura tradicional caiçara, o que é visto pelos representantes das associações como o meio para se reivindicar o reconhecimento do território e se manter no loc

\section{CONSIDERAÇÕES FINAIS}

Conclui-se que o uso público traz benefícios para as Unidades de Conservação, conferindo visibilidade e reconhecimento da importância do ambiente natural, mas quando não há gestão adequado, o turismo de massa pode impactar negativamente o ambiente, reduzindo a qualidade do ambiente e impactando no próprio uso, quando a degradação da natureza provocada pelo visitante desestimula a visitação, e na comunidade local.

Neste sentido, fica evidente que o uso público no litoral do PNSB precisa ser melhor planejado e ordenado, pois as ações realizadas pelos gestores da UC não estão sendo efetivas. Logo, ações de educação e interpretação ambiental, promovidas pelos gestores do Parque em associação com a comunidade local, podem ser alternativas para redução dos impactos do uso público.

Ainda há necessidade de avançar nos estudos sobre geoturismo e geodiversidade dentro de Unidades de Conservação, já que, na maioria das vezes os gestores e os visitantes, não sabem que nas UCs existem

$\begin{array}{lllll}\text { Caminhos de Geografia } & \text { Uberlândia } & \text { v. 20, n. } 72 & \text { Dez/2019 } & \text { p. 506-521 Página } 518\end{array}$


sítios de geodiversidade e geossítios e qual a importância dos mesmos não só como atrativos, mas também, para a manutenção do geossistema.

A avaliação do potencial geoturístico do litoral do Parque Nacional da Serra da Bocaina mostra que os sítios de geodiversidade, principalmente a piscina natural Caixa D'Aço, necessitam de estratégias para sua conservação. Além disso, é necessário investir na divulgação da importância do patrimônio geológico e geomorfológico para o sistema ambiental.

Fica evidente que a implantação de um programa de geoturismo dentro do PNSB pode diversificar o uso público atual, reduzindo os impactos observados por meio de ações de interpretação ambiental e de valorização da geodiversidade local.

Por fim, destaca-se que a pesquisa realizada irá auxiliar na gestão do Parque, se forem realizadas ações integradas dos gestores da UC com a comunidade local, que busca, divulgar a importância da cultura caiçara para os turistas. Esse tipo de valorização da comunidade local é um dos preceitos do geoturismo. Comprova-se assim, principalmente para os gestores, que é de suma importância realizar um estudo integrado a fim de se obter o maior sucesso possível nas intervenções feitas.

\section{AGRADECIMENTOS}

Agradecimentos ao Conselho Nacional de Desenvolvimento Científico e Tecnológico (CNPq) e à Fundação de Amparo à Pesquisa do Estado do Rio de Janeiro (FAPERJ) pelo financiamento da pesquisa no período de 2012 até 2017; e à Coordenação de Aperfeiçoamento de Pessoal de Nível Superior (CAPES) pelo financiamento da bolsa de doutorado de 2014 até fevereiro de 2018.

\section{REFERÊNCIAS}

AVELAR S, VASCONCELOS C, MANSUR KL ANJOS S, VASCONCELOS, G. Targeting Sustainability Issues at Geosites: a Study in Região dos Lagos, Rio de Janeiro, Brazil. Geoheritage. v. 10, n. 1, p. 1-9, 2018. https://doi.org/10.1007/s12371-016-0212-1

BENTO, L. C. M.; RODRIGUES, S. C. Geoturismo em unidades de conservação: uma nova tendência ou uma necessidade real? - estado da arte. Revista do Departamento de Geografia - USP, v. 25, p. 77-97, 2013. https://doi.org/10.7154/RDG.2013.0025.0105

BRILHA, J. Geoconservation, Concept of. In: TIESS, G.; MAJUMDER, T.; CAMERON, P. (Eds). Encyclopedia of Mineral and Energy Policy. Springer-Verlag Berlin Heidelberg, 2015. https://doi.org/10.1007/978-3-642-40871-7 2-1 . Inventory and Quantitative Assessment of Geosites and Geodiversity Sites: a Review.

Geoheritage, v. 8, n. 2, p. 119-134, 2016. https://doi.org/10.1007/s12371-014-0139-3

CONTI, B.R. Proteção da Natureza e Qualidade de Vida em Trindade (Paraty - RJ): para entender o ecoturismo no Parque Nacional da Serra da Bocaina. 2011. 207p. Dissertação (Mestrado em Psicossociologia de Comunidades e Ecologia Social) - Instituto de Psicologia, Universidade Federal do Rio de Janeiro (UFRJ), Rio de Janeiro - RJ, 2011.

CONTI, B.R.; IRVING, M.A.; CORRÊA, F.V. Parque Nacional da Serra da Bocaina/RJ: Qual a relação com a Vila de Trindade? In: Anais do VIII Congresso Nacional de Ecoturismo e do IV Encontro Interdisciplinar de Ecoturismo em Unidades de Conservação. Revista Brasileira de Ecoturismo, São Paulo, v.4, n.4, 2011, p. 503. https://doi.org/10.34024/rbecotur.2011.v4.5937

CONTI, B. R.; ANTUNES, D. C. Conflitos na gestão do Parque Nacional da Serra da Bocaina: entraves ao desenvolvimento local na vila de Trindade (Paraty, RJ). Revista Interações, Campo Grande, v. 13, n. 2, p. 213-223, jul./dez. 2012. https://doi.org/10.1590/S1518-70122012000200008

CONTI, B.R.; IRVING, M.A. Desafios para o ecoturismo no Parque Nacional da Serra da Bocaina: o caso da Vila de Trindade (Paraty, RJ). Revista Brasileira de Ecoturismo, São Paulo, v.7, n.3, p.517-538, 2014. https://doi.org/10.34024/rbecotur.2014.v7.6400

$\begin{array}{lllll}\text { Caminhos de Geografia } & \text { Uberlândia } & \text { v. 20, n. } 72 & \text { Dez/2019 } & \text { p. 506-521 Página } 519\end{array}$


DOWLING, R. K. Global geotourism - an emerging form of sustainable tourism. Czech Journal of Tourism, v. 2, n. 2, p. 59-79, 2013. https://doi.org/10.2478/cjot-2013-0004

DOWLING, R.; NEWSOME, D. Geotourism's issues and challenges. In: DOWLING, R.; NEWSOME, D. (Org.) Geotourism. Elsevier Butterworth Heinemann, Oxford. 2006. 260 p. https://doi.org/10.4324/9780080455334

FORTE, J.P., BRILHA, J., PEREIRA, D.I. NOLASCO, M. Kernel Density Applied to the Quantitative Assessment of Geodiversity. Geoheritage, p. 1-13, 2018. https://doi.org/10.1007/s12371-018-0282-3

GRAY, M. Geodiversity and Geoconservation: what, why, and how? The George Wright Forum, p.4-12, 2005. Disponível em: http://www.georgewright.org/223gray.pdf. Acesso em: 10 mai 2017.

https://doi.org/10.1016/S0016-7878(08)80307-0

GRAY, M. Geodiversity: developing the paradigm. Proceedings of the Geologists' Association, v. 119, n. 3- 4, p. 287-298, 2008.

GRAY, M. Geodiversity: valuing and conserving abiotic nature. 2 ed. Chichester: John Wiley \& Sons, 2013, p. 495.

GUERRA, A. J. T.; JORGE, M. C. O.; FULLEN, M. A. BEZERRA, J. F. R. The gomorphology of Angra dos Reis and Paraty municipalities, Southern Rio de Janeiro State. Revista Geonorte, v.9, n.1, p.1-21, 2013.

HOSE, T. A. Geotourism and Interpretation. In: DOWLING, R. E.; NEWSOME, D. (Org.) Geotourism. Elsevier Butterworth Heinemann, Oxford. 2006. 260 p. https://doi.org/10.1016/B978-0-7506-62154.50020-8

ICMBIO - INSTITUTO CHICO MENDES DE BIODIVERSIDADE. Piscina natural terá limite de visitantes em Parque Nacional. 2014. Disponível em:

http://www.icmbio.gov.br/portal/comunicacao/noticias/4-destaques/4926-piscina-natural-tera-limite-devisitantes-em-parque-nacional.html. Acesso em: 15 dez.2014.

ICMBIO - INSTITUTO CHICO MENDES DE BIODIVERSIDADE. Parque Nacional Da Serra da Bocaina promoveu ação de ordenamento turístico na Trindade. 2017. Disponível em:

http://www.icmbio.gov.br/parnaserradabocaina/ destaques/ 152-parque-nacional-da-serra-da-bocainapromoveu-acao-de-ordenamento-turistico-na-trindade.html. Acesso em: 24 mar 2017.

JORGE, M. C. O. Potencial geoturístico e estratégias de geoconservação em trilhas situadas na região sul do município de Ubatuba - SP. 242 f. 2017. Tese (Doutorado em Geografia) - Programa de Pós-Graduação em Geografia, Instituto de Geociências, Universidade Federal do Rio de Janeiro, Rio de Janeiro, 2017.

JORGE, M. C. O.; GUERRA; A. J. T. Geodiversidade, geoturismo e Geoconservação: Conceitos, Teorias e Métodos. Revista Espaço Aberto. v. 6, n.1, p. 151-174, 2016.

https://doi.org/10.36403/espacoaberto.2016.5241

LOPES, L. S. O.; ARAÚJO, J. L.; CASTRO, A. J. F. Geoturismo: Estratégia de Geoconservação e de Desenvolvimento Local. Caderno de Geografia, v.21, n.35, 2011.

LOUREIRO, H. A. S.; RANGEL, L. A.; GUERRA, A. J. T. Uso público em Unidades de Conservação: atividade ecoturística no litoral do Parque Nacional da Serra da Bocaina - Paraty (RJ) In: VIII SEMINÁRIO BRASILEIRO SOBRE ÁREAS PROTEGIDAS E INCLUSÃO SOCIAL / III ENCONTRO LATINOAMERICANO SOBRE ÁREAS PROTEGIDAS E INCLUSÃO SOCIAL. Anais ... Niterói, 2017.

MMA - MINISTÉRIO DO MEIO AMBIENTE. Plano de Manejo do Parque Nacional da Serra da

Bocaina. Instituto Brasileiro de Meio Ambiente. Diretoria de Ecossistemas/Departamento de Unidades de Conservação. Brasília: Ministério do Meio Ambiente, 2002. Disponível em:

http://www.icmbio.gov.br/parnaserradabocaina/extras/62-plano-de-manejo-e-monitorias.html . Acesso em: 4 jan. 2012.

NASCIMENTO, M.A.L.; MANSUR, K.L.; MOREIRA, J. C. Bases conceituais para entender geodiversidade, patrimônio geológico, geoconservação e geoturismo. Anais do XVI Simpósio Brasileiro de Geografia Física Aplicada, Teresina, 2015.

PONÇANO, W. L. et al. Mapa Geomorfológico do Estado de São Paulo - escala 1:500.000. São Paulo: Instituto de Pesquisas Tecnológicas. 1981. 1 mapa. p. 94.

Caminhos de Geografia Uberlândia $\quad$ v. 20, n. $72 \quad$ Dez/2019 $\quad$ p. 506-521 Página 520


RANGEL, L. A.; GUERRA, A. J. T.; BOTELHO, R. G. M. Potencial Geoturístico em Unidades de Conservação da Costa Verde (estado do Rio de Janeiro): o Parque Nacional da Serra da Bocaina e o Parque Estadual Cunhambebe In: Anais I Workshop Arte \& Ciência - Reflexão integrada no percurso histórico da paisagem. 2017. Disponível em:

https://conferencias.ufrj.br/index.php/wac/wap2017/paper/download/1663/27. Acesso em: 01 jul. 2019.

RANGEL, L. A. Geoturismo em Unidades de Conservação: a utilização de trilhas no litoral do Parque Nacional da Serra da Bocaina - Paraty (RJ). 223f. 2018. Tese (Doutorado em Geografia) Departamento de Geografia, Universidade Federal do Rio de Janeiro, Rio de Janeiro, 2018

RANGEL, L. A.; GUERRA, A. J. T. Caracterização de atributos do solo de trilhas ecoturísticas em Unidades de Conservação do município de Paraty, estado do Rio de Janeiro. Revista Brasileira de Geomorfologia. v.19, p.17 - 31, 2018. https://doi.org/10.20502/rbg.v19i1.1134

RODRIGUES, J. de C. Geoturismo: uma abordagem emergente. In: CARVALHO, C. N. de; RODRIGUES, J; JACINTO, A. (Org.) Jornadas sobre a fundação social museu, XVIII. Portugal. Geoturismo e desenvolvimento local. Portugal: 2008, p. 38-61.

RODRIGUES, A. M.; RANGEL, L. A.; PEREIRA, L. S.; JORGE, M. C. O.; MOLINARO, Y. T.; GUERRA, A. J. T. Degradação dos solos em diferentes usos (trilha e taludes de corte) em unidades de conservação. XI SINAGEO, Maringá - 15 a 21 de Setembro. 2016. Anais... Disponível em:

http://www.sinageo.org.br/2016/trabalhos/8/8-368-393.html. Acesso em: 12 jan. 2017.

SANTOS, E. M. Diagnóstico da geodiversidade e potencial geoturístico do município de Bonito, agreste de Pernambuco. 2012. 113f. Dissertação (Mestrado em Geociências). - Departamento de Geociências, Universidade Federal de Pernambuco, Pernambuco, 2012.

SANTOS, L. B. Percepção ambiental e conflitos de uso dos recursos naturais em áreas protegidas: um estudo no Parque Nacional da Serra da Bocaina. 2016. 202. Tese (Doutorado em Geografia) Departamento de Geografia, Universidade Federal do Rio de Janeiro, Rio de Janeiro, 2016.

VALLEJO, L. R. Uso público em áreas protegidas: atores, impactos, diretrizes de planejamento e gestão. Uso Público em Unidades de Conservação, v. 1, p. 13-26, 2013.

Recebido em: 29/01/2019

Aceito para publicação em: 12/08/2019 